\title{
Communicating with the public about the risks of naturally occurring asbestos
}

\section{Claire Hookera,c, Adam Capon ${ }^{\mathrm{b}}$ and Isabel MR Hess ${ }^{\mathrm{b}}$}

a Sydney Health Ethics, University of Sydney, NSW, Australia

b Health Risk and Regulation Unit, Health Protection NSW, NSW Health, Sydney, Australia

c Corresponding author: claire.hooker@sydney.edu.au

\section{Article history}

Publication date: December 2017

Citation: Hooker C, Capon A, Hess IMR.

Communicating with the public about the risks of naturally occurring asbestos. Public Health Res Pract. 2017;27(5):e2751747. https://doi.org/10.17061/phrp2751747

\section{Key points}

- Governments need to be patient with communities and willing to invest the time for public discussion of community concerns

- Regardless of how well crafted a risk communication strategy is, the communicator cannot control how a message will be received

- Public concern and outrage can be reduced by actions such as favouring early and frequent communication, open acknowledgement of uncertainty, and supporting community action

\section{Abstract}

Objectives: To explore the application of evidence based risk communication to community messaging about naturally occurring asbestos (NOA).

Type of program or service: Risk communication education about NOA.

Methods: We apply principles and determinants of risk communication to the topic of NOA.

Results: We emphasise the importance of erring on the side of transparency and trust, even when officials may be concerned about inadvertently heightening needless public concern. We offer a range of practical suggestions for how to lower public concern and outrage relating to the issue of NOA when it arises in local contexts.

Lessons learnt: Public concern and outrage can be reduced by favouring early and frequent communication, awareness and use of the 'rule of threes' in media communication, open acknowledgement of uncertainty, prioritising response to community concern above narrow myth-busting strategies, and supporting community action.

\section{Introduction}

In New South Wales (NSW), Australia, the state government takes a wholeof-government approach to managing asbestos. The government formed the Heads of Asbestos Coordination Authorities (HACA), an interagency group that consists of multiple NSW Government agencies and representatives from local government.

To support this holistic approach, HACA has published maps that indicate where naturally occurring asbestos (NOA) is likely to be found across NSW. ${ }^{1}$ The maps will help the government to identify areas that residents may wish to avoid, or undertake activities in with extra precautions, and to track changes in the incidence of asbestosis, mesothelioma and baseline lung cancers in NOA areas.

Asbestos is the name given to a group of naturally occurring fibrous minerals found in rock formations in Australia and around the world. It is ubiquitous in air. Known for its strength, heat resistance and insulating 
properties, asbestos was mined in and imported into Australia during the past century. It was used in products such as asbestos cement ('fibro') roof, wall and fence sheeting; vehicle brakes; and spray-on heat insulation. As a result of increasing evidence of its link with lung cancers, most asbestos types were banned from import or use by the mid-1980s, with a final ban enforced on all types in December 2003.²

NOA refers to the veins, aggregates and individual crystals of asbestos mineral that occur within the rock formations of Earth's crust. It is this mineral that was mined to produce asbestos products. Approximately $1 \%$ of the land mass of NSW has the potential to contain NOA, mostly in very low concentrations.

Appropriate risk communication has been established as a key determinant of compliance with safety recommendations and of managing unnecessary community alarm relating to NOA. ${ }^{3} \mathrm{NOA}$ has raised concerns in local communities in the past ${ }^{4-5}$, but there are very few studies of health education and risk communication strategies with respect to this topic. ${ }^{4} \mathrm{We}$ provide practical guidance for risk communication about NOA, to complement and support the fact sheets and educational video currently provided by HACA. ${ }^{6}$

\section{Health risks of asbestos}

Breathing in asbestos fibres is known to cause cancer, specifically mesothelioma and lung cancer, as well as asbestosis. Mesothelioma is an aggressive form of cancer that manifests decades after initial exposure, with only a $40 \%$ survival rate beyond a year of diagnosis. Asbestosis involves scarring of the lungs that severely restricts breathing.

However, breathing in asbestos fibres does not mean that someone will develop an asbestos-related disease. The risk of disease varies between individuals and depends on how many fibres have been breathed in and for how long, the fibre type, smoking status and age at exposure. It is estimated that we breathe in up to 3000 asbestos fibres a day through normal background exposure. Despite this exposure, very few people experience ill effects. Most people who develop asbestos-related disease have been exposed to much higher concentrations of asbestos, generally from working with asbestos or asbestos products. ${ }^{7}$

The risk of developing an asbestos-related disease from NOA is considered low for residents in NSW. ${ }^{8}$ Epidemiological evidence from countries that have similar cultural practices to Australia have found a low but increased risk of developing mesothelioma ${ }^{9}$, although these findings are disputed as potentially overstating the risk because they have methodological problems. In countries that have differing cultural practices to Australia, such as whitewashing house walls with asbestos, evidence of an increased risk of mesothelioma has been found. ${ }^{10}$
Because low exposure to asbestos is ubiquitous, yet causes little or no disease, merely living in an area with NOA is regarded by public health officials as being low risk. However, in the public sphere, considerable prominence has been given to the myth that 'one fibre can kill'. This is a prominent view among high-profile asbestos activists, health and safety campaigners, unions, and individuals concerned about the global asbestos death toll, and may well be a component of many 'mental models'11 of asbestos and NOA risk held by members of the public.

Working with communities in an NOA area therefore presents a particular kind of risk communication challenge - one in which the probability of the risk is low, but the public may perceive it as very high, particularly in situations where asbestos risks become suddenly salient to a community. Low-probability, high-consequence risks prompt differing levels of defensive reaction from audiences with differing degrees of risk aversion, and have caused significant community controversy in the past. ${ }^{4}$

\section{Risk communication and naturally occurring asbestos}

\section{Risk versus outrage}

Health risk communication falls into one of four categories, whose parameters are defined by the severity of the risk on one axis, and by the degree of public anxiety about it on the other. ${ }^{3}$ Each category of risk communication - high risk, high outrage (e.g. epidemic Ebola virus disease); low risk, low outrage (e.g. aflatoxins in food); high risk, low outrage (e.g. sitting, sugar consumption); and low risk, high outrage (e.g. immunisation) - requires its own strategies. NOA is largely a low-risk, low-outrage issue. Under these circumstances, communication is best kept to a strictly educational focus, as has been the case in NSW thus far, to prevent 'iatrogenic' concerns - that is, public concerns that are generated by the act of communicating itself. Fact sheets on an appropriate website ${ }^{6}$ provide information for those who need it without raising the public profile of the issue.

Prominent media uptake of maps identifying specific locations for NOA has the potential to transform this, at least briefly, into a low-risk, high-outrage issue. ${ }^{12}$ This situation is most likely to arise when local circumstances, such as road or building works, raise the salience $e^{3,12,13}$ of the issue and increase the profile of the risk.

The goals of risk communication in this situation will be to address and minimise public concerns - that is, to reduce outrage and build trust ${ }^{13}$, as well as to give factual information about NOA. 


\section{Applying risk communication principles to naturally occurring asbestos}

The basic principles for best practice in risk communication are now well established ${ }^{3}$, and include:

- Be adequately prepared

- Accept and involve the public in communication and decision making

- Be honest, frank and open

- Communicate early and often., 3,12,13

Negative dominance theory and mental noise theory predict that when people are upset or outraged, they have difficulty hearing and processing information ${ }^{14}$, so addressing any fear or outrage should be the most pressing task. People will need to hear and see that their concerns have been understood and respected before they will listen to any response. Initial phases of risk communication involve the communicator doing a lot of active listening.

\section{Factors influencing public risk perception of naturally occurring asbestos}

Good risk communication will begin with anticipation of what cognitive heuristics and biases will influence how the risks of asbestos are likely to be perceived. ${ }^{11,13}$

The causative link between asbestos and cancer is familiar to many Australians, and cancer is viewed by the public with dread and fear. ${ }^{15}$ The cancer risks of asbestos gained prominence in media and public discourse over several decades through the mobilisation of asbestos victims and activists for banning asbestos. Possibly the most heuristically 'available' 13,14 media representations of asbestos in Australia have been associated with the long-time anti-asbestos advocate and campaigner Bernie Banton. Extensive media coverage followed the progress of Banton, who first developed asbestosis and, later, mesothelioma. This coverage was framed around the notion of 'one fibre can kill'. It is therefore likely that many Australian mental models of asbestos risk will associate any exposure with a high probability of a dreaded death from cancer.

\section{Practical risk communication for}

\section{NOA}

\section{Take action}

Actions are the strongest form of communication. ${ }^{3}$ This means that the action of creating maps of NOA in NSW may be interpreted as an indication of high risk (regardless of their content). Therefore, an accompanying message that the risks of NOA are low may seem contradictory. If, instead, the maps are presented as a key tool for HACA to prevent and minimise the risk of exposure to asbestos, public trust can be maintained, as has thus far been the case.
Similarly, the actions of good preparation for responding to public concern will help develop public trust in HACA and local health agencies, and, consequently, be a determinant of perceptions of the risks of NOA. If concerned members of the public cannot access clear, competent and consistent information about the risks of NOA immediately and at the level of detail they prefer, they are likely to interpret risk messages within dominant mental models of asbestos that emphasise outrage and mistrust. By contrast, actions (such as helplines, accessible web pages with levels of detailed information and the provision of accurate, helpful information to on-the-ground local health staff) indicate competency, authentic concern for the public, and transparency.

Some members of the public may feel that they have little control over the risks posed by NOA, and this may heighten their perception of risk. ${ }^{13}$ In these cases, suggesting specific protective actions offers people a way to re-establish a sense of control. Decision aids can be helpful ways to support public reactions to risk information. ${ }^{3,16}$ These can include information-gathering actions that support public confidence in an overall message about the low risk from NOA.

\section{Accept and address public concerns}

Trying to correct public misperceptions by 'myth busting' can be detrimental, because people often feel their concerns have been simply dismissed. Additionally, research indicates that attempts to bust myths can perpetuate rather than diminish these myths, partly by simply reiterating them. ${ }^{17}$

A better risk communication strategy is to acknowledge the public's concerns and indicate how they are being addressed by the current strategies. ${ }^{3,12}$ For example, risk communicators might point out that, because people have not been well informed about NOA and asbestos risks in the past, HACA has developed these maps and accompanying literature so that people can monitor, understand and make their choices according to their own level of comfort and security.

\section{Communicate early and often}

The best ways to have a message reflected in media reporting are to meet the needs of journalists and to anticipate and respond early to the needs of communities. This enables 'capture' over the issue (that is, the opportunity to choose the terms on which the issue will be defined ${ }^{18}$ ).

Engage early, even if this risks generating overreactions (see below); these will be much more temporary than the effects of the issue being defined on the terms set by a political, industrial or activist agenda. It is important for HACA to have a clear story and ensure that experts are instantly available to journalists to control the story's framing. ${ }^{19,3}$ Engaging influential journalists and social media groups can also help to ensure that 
available information is accurate and is the subject of thoughtful public discussion.

Asbestos-related illness has been a high-outrage, highly politicised issue, and advocates may be highly suspicious of government communications. A highprofile anti-asbestos advocate or a trusted, independent public figure may be especially useful.,4,12,14 Alternatively, friends, family and community more strongly determine an individual's risk perception than a government agency. Investing time in local community-driven responses such as an annual schoolground inspection - builds multiple benefits such as increased public trust, public compliance and social capital. ${ }^{3}$

\section{Tolerate early overreactions}

Initial risk communication usually produces a reaction, but such reactions are usually short lived. ${ }^{18}$ HACA will need to provide public access to information from a range of sources, and offer a suite of potential active responses as people work through their concerns.

\section{Communicate uncertainty}

For NOA, it is important to acknowledge the possibility, however unlikely, that someone may develop an asbestos-related disease from NOA exposure, and to emphasise that most cases of asbestos-related disease arise from occupational exposure to much higher concentrations of asbestos. Communication should state that, even though disease from exposure to NOA is highly unlikely, it is still possible, and these maps will help to pinpoint known areas where risks may be higher than normal, so that remediating actions can occur.

The risk posed by NOA was judged as 'low' as a result of HACA's own careful deliberation about the most correct choice of terminology. It is important to recognise that members of the public may want to know what 'low' means in more concrete terms, such as numbers of deaths or incidence rates of mesothelioma. This question may be prompted by hearing claims made about the relative risks as opposed to the absolute risks of developing asbestos-related disease, or by anecdotes about cases with no clearly identifiable cause. If the communicator then refused to, or could not, explain the grounds by which experts have judged the risk to be 'low' (presumably out of concern to prevent confusion and misinformation), this could swiftly amplify public mistrust and concern. Consequently, we emphasise the longterm usefulness of communicating clearly that, because of the limits of epidemiological methods and geological mapping, some uncertainty will always remain. Giving people a range of actions so they can select what best fits their tolerance for this risk, and making the technical information available for those who wish to seek and understand it, will help constructive risk communication.

\section{Identify and reduce fright factors}

Risks we dread are those that we lack control over, or perceive as unfamiliar or inequitable. Emphasising that asbestos is natural, has been known about for centuries, is highly familiar to science, and can be managed by communities will help build mental models of NOA that distinguish it from occupational exposures.

\section{Use the rule of threes and deliver messages clearly}

Communicate by the 'rule of threes': three key messages, repeated three times, with each supported by three additional messages from three credible sources. ${ }^{14,20}$ This scaffolding helps audiences retain messages when conditions of stress and outrage reduce their capacity for information processing. Research indicates that when people are stressed and upset, they have limited capacity to process information. Therefore, the language used in risk communication messages must be accessible at low functional literacy levels and be delivered clearly.

\section{Conclusion}

It is important to remember that, regardless of how well crafted a risk communication strategy is, the communicator cannot control how it will be received. No matter what the content of a message, it is open to different interpretations by different audiences, who may be apathetic, suspicious, critical, sceptical or supportive. The government needs to be aware of this, be patient with the community and be willing to invest the time to talk about concerns. There is extensive evidence that indicates that, in the end, this strategy reaps rewards.

\section{Competing interests}

None declared

\section{Author contributions}

$\mathrm{CH}$ led the writing of the manuscript and remained in charge of its structure and argument. AC contributed to all sections about technical information and the history of asbestos and asbestos-related diseases. AC and $\mathrm{IH}$ edited and checked for technical accuracy, and supplied further information as needed.

\section{References}

1. Heads of Asbestos Coordination Authorities. Mapping of naturally occurring asbestos in NSW: known and potential for occurrence. Sydney: State of New South Wales through the Heads of Asbestos Coordination Authorities; 2015 [cited 2017 Oct 26]. Available from: www.safework. nsw.gov.au/_data/assets/pdf_file/0006/56778/WC017880715-297174.pdf 
2. enHealth. Management of asbestos in the nonoccupational environment. Canberra: Australian Government; 2005 [cited 2017 Nov 24]. Available from: www.health.vic.gov.au/archive/archive2014/nphp/ enhealth/council/pubs/pdf/asbestos.pdf

3. Hooker C, Leask J, Capon A. Communicating about risk: strategies for situations where public concern is high but the risk is low. Public Health Res Pract. 2017;27(1):e2711709.

4. Culley MR, Zorland J, Friere, K. Community responses to naturally occurring asbestos: implications for public health practice. Health Educ Res. 2010;25(5):877-91.

5. Lee RJ, Strohmeier BR, Bunker KL, Van Orden DR. Naturally occurring asbestos: a recurring public policy challenge. J Hazard Mater. 2008;153(1-2):1-21.

6. SafeWork NSW. Sydney: NSW Government. Naturally occuring asbestos. [cited 2017 Jul 31]; [about 2 screens]. Available from: www.safework.nsw.gov.au/ health-and-safety/safety-topics-a-z/asbestos/naturallyoccurring-asbestos

7. Heads of Asbestos Coordination Authorities. SafeWork NSW. Sydney: NSW Government. Residing in areas of naturally occurring asbestos factsheet [cited 2017 Oct 26]; [about 3 screens]. Available from: www. safework.nsw.gov.au/health-and-safety/safety-topicsa-z/asbestos/naturally-occurring-asbestos/naturallyoccurring-asbestos-publications/residing-in-areas-ofnaturally-occurring-asbestos-factsheet2

8. Baumann F, Buck BJ, Metcalf RV, McLaurin BT, Merkler DJ, Carbone M. The presence of asbestos in the natural environment is likely related to mesothelioma in young individuals and women from Southern Nevada. J Thorac Oncol. 2015;10(5):731-7.

9. Pinheiro PS, Jin $\mathrm{H}$. No increased risk for mesothelioma in relation to natural-occurring asbestos in Southern Nevada. J Thorac Oncol. 2015;10(7):e62-3.

10. Constantopoulos SH, Malamou-Mitsi VD, Goudevenos JA, Papathanasiou MP, Pavlidis NA, Papadimitriou CS. High incidence of malignant pleural mesothelioma in neighbouring villages of Northwestern Greece. Respiration. 1987;51(4):266-71.
11. Morgan MG, Fischoff B, Bostrom A, Altman C. Risk communication: a mental models approach. Cambridge and New York: Cambridge University Press; 2002.

12. The Peter M. Sandman Risk Communication Website. Brooklyn: Peter M. Sandman. Introduction to risk communication; 2014 [cited 2015 Oct 6]; [about 7 screens]. Available from: www. psandman.com/indexintro.htm

13. Slovic P. The perception of risk. London and Sterling, Va: Earthscan Publications; 2000.

14. Covello VT, Milligan PA. Risk communication: principles, tools and techniques. Rockville, MD: United States Nuclear Regulatory Commission; 2010 [cited 2017 Oct 26]. Available from: www.nrc.gov/docs/ML1015/ ML101590283.pdf

15. MacTiernan A, Fritschi L, Slevin T, Jalleh G, Donovan R, Heyworth J. Public perceptions of cancer risk factors: a Western Australian study. Health Promot J Aust. 2014;25(2):90-6.

16. Trevena L, Zikmund-Fisher B, Edwards A, Gaissmaier W, Galesic M, Han PK, et al. Presenting quantitative information about decision outcomes: a risk communication primer for patient decision aid developers. BMC Med Inform Decis Mak. 2013;13(Supplement 2):S7.

17. Heath C, Heath D. Made to stick: why some ideas survive and others die. Sydney: Random House; 2007.

18. Leiss W. In the chamber of risks: understanding risk controversies. Montreal: McGill-Queen's University Press; 2001. 388 p.

19. Hooker C, Leask J, King C. Media coverage of health issues and how to work more effectively with journalists: a qualitative study. BMC Public Health. 2010;10:1-7.

20. Covello VT, McCallum DB, Pavlova MT, Task Force on Environmental Cancer and Heart and Lung Disease (US). Effective risk communication: the role and responsibility of government and nongovernment organizations. New York: Plenum; 1989. 370 p.

\section{Copyright: (c)}

(C) 2017 Hooker et al. This article is licensed under the Creative Commons Attribution-NonCommercial-ShareAlike 4.0 International Licence, which allows others to redistribute, adapt and share this work non-commercially provided they attribute the work and any adapted version of it is distributed under the same Creative Commons licence terms. See: www.creativecommons.org/licenses/by-nc-sa/4.0/ 